\title{
Landmark Values of Equatorial Electrojet Current and Magnetic Field along a Meridian near Noon
}

\author{
C. A. Onwumechilit ${ }^{1}$, P. C. Ozoemena ${ }^{1}$, and C. E. $\mathrm{AGU}^{2}$ \\ ${ }^{1}$ Anambra State University of Technology, PMB 01660, Enugu, Nigeria \\ ${ }^{2}$ Institute of Management and Technology, Enugu, Nigeria
}

(Received March 17, 1988; Revised November 28, 1988)

\begin{abstract}
Landmark values of the equatorial electrojet: the minimum intensity $J_{\mathrm{m}} \mathrm{A} \cdot \mathrm{km}^{-1}$, its distance $x_{\mathrm{m}} \mathrm{km}$ and ratio to maximum intensity $J_{\mathrm{m}} / J_{0}$; the magnetic field constant $K \mathrm{nT}$; the maximum northward magnetic field $X_{0} \mathrm{nT}$, and the distance of zero northward magnetic field $w_{X} \mathrm{~km}$; the minimum northward magnetic field $X_{\mathrm{m}} \mathrm{nT}$, its distance $u_{\mathrm{m}} \mathrm{km}$ and ratio to maximum northward field $X_{\mathrm{m}} / X_{0}$; the vertical magnetic field $Z_{0} \mathrm{nT}$ at the dip equator and the distance of zero vertical field $w_{z} \mathrm{~km}$; the maximum vertical magnetic field $Z_{\mathrm{M}} \mathrm{nT}$, its distance $u_{\mathrm{M}} \mathrm{km}$ and ratio to maximum northward field $Z_{\mathrm{M}} / X_{0}$; have all been derived from September equinox satellite data and they compare favourably with their values from ground-based data. Our $J_{\mathrm{m}} / J_{0}$ agrees excellently with MUSMANN and SEILER (1978) and ANANDARAO and RAGHAVARAO (1979); while our $x_{\mathrm{m}}$ agrees excellently with the location of CAHILL's (1959) westward current, and the findings of MUSMANN and SEILER (1978). The landmark distances $x_{\mathrm{m}}, w_{X}, u_{\mathrm{m}}, u_{\mathrm{M}}, w_{Z}$ and the ratios $J_{\mathrm{m}} / J_{0}, X_{\mathrm{m}} / X_{0}$ and $Z_{\mathrm{M}} / X_{0}$ do not vary with longitude but the intensity $J_{\mathrm{m}}$ and magnetic fields, $K, X_{0}, X_{\mathrm{m}}, Z_{0}$ and $Z_{\mathrm{M}}$ have maxima around $90^{\circ} \mathrm{E}, 180^{\circ} \mathrm{E}$ and $270^{\circ} \mathrm{E}$; and minima around $155^{\circ} \mathrm{E}$ and $225^{\circ} \mathrm{E}$.
\end{abstract}

\section{Introduction}

For a long time it has not been possible to determine from ground data all the parameters of a model of equatorial electrojet put forth as far back as 1965 (ONWUMECHILI, 1965, 1966, 1967). Consequently, its view of the equatorial electrojet (EEJ) could not be fully examined. With the help of satellite and rocket data we have now determined all the parameters, though naturally, some of them more reliably than others, because rocket data are much scarcer than satellite data.

It has therefore become possible for the first time to almost fully explore the model's view of the EEJ as well as its implications for the equatorial electrojet. In this paper we explore certain landmark values of the equatorial electrojet current and magnetic field along a meridian of longitude near local noon, that have so far not been reliably studied.

Recently, Onwumechili and Ozemena obtained some of the parameters from the analysis of 17 rocket flights into the EEJ. These are used in conjunction with other parameters determined from POGO satellite data of the September equinoxes 
of 1967, 1968 and 1969 by ONWUMECHILI and AGU (1981). The resulting landmark values are then compared with their other observations, as well as determinations existing in scientific literature.

\section{Minimum Current Intensity}

The model can be reduced to a form suitable for the study of latitudinal variation of the eastward height-integrated current density (called intensity $J$ ), which is given by

$$
J=J_{0} \frac{a^{2}\left(a^{2}+\alpha x^{2}\right)}{\left(a^{2}+x^{2}\right)^{2}} .
$$

$J$ has a minimum value $J_{\mathrm{m}}$ at a distance $x_{\mathrm{m}}$ from the magnetic dip equator, where

$$
J_{\mathrm{m}}=J_{0} \alpha^{2} / 4(\alpha-1) \quad \text { and } \quad x_{\mathrm{m}}^{2}=a^{2}(\alpha-2) / \alpha .
$$

For the POGO equinox data ONWUMECHILI and AGU (1981) have studied the peak eastward current intensity $J_{0}$, at the axis of the EEJ above the magnetic dip equator at $x=0$, while ONWUMECHILI and OzOEMENA (1985) studied the meridional scale length $a$ and the meridional distribution parameter $\alpha$ which controls the distribution of current along a meridian.

With values of $J_{0}, a$ and $\alpha$ determined by Onwumechili and Agu and given in ONWUMECHILI and AGU (1981) and ONWUMECHILI and OzOEMENA (1985), we have calculated $J_{\mathrm{m}}$ and $x_{\mathrm{m}}$ from Eq. (2) at $10^{\circ}$ intervals of east longitude. The results are given in Table 1 , and their means for $30^{\circ}$ sectors are plotted in Fig. 1. The ratio of the minimum intensity $J_{\mathrm{m}}$ to the maximum intensity $J_{0}$ is also given in Table 1 in percentage.

\section{Northward Magnetic Field Component of the Equatorial Electrojet}

On evaluating the double integrals of the expressions for the current density of the EEJ over the altitude and latitude extents of the EEJ, the model gives complicated expressions for the northward component $X$ and the vertical component $Z$ of the magnetic field of the equational electrojet. On certain assumptions, the northward component may be approximated to

$$
\text { (sg. } z) X=\frac{1}{2} K a \frac{(v+\alpha v+2 \alpha a)(u+b)^{2}+(v+\alpha v+2 a)(v+a)^{2}}{\left[(u+b)^{2}+(v+a)^{2}\right]^{2}},
$$

where $x$ is the northward distance from the axis of the EEJ and $u$ is the magnitude of $x, z$ is the vertically downward distance from the axis of the EEJ and $v$ is the magnitude of $z, b$ is the vertical scale length of the EEJ and (sg. $z$ ) is the sign of $z$. 
Table 1. Showing equatorial electrojet $J_{\mathrm{m}} \mathrm{A} \cdot \mathrm{km}^{-1}$, minimum eastward current intensity (here westward); $J_{\mathrm{m}} / J_{0}$, percentage of peak westward to peak eastward intensity; $K \mathrm{nT}$, magnetic field constant; $X_{0}$ $\mathrm{nT}$, maximum northward magnetic field; and distances: $x_{\mathrm{m}} \mathrm{km}$, from dip equator to minimum intensity; $w_{X} \mathrm{~km}$, from dip equator to zero northward magnetic field; $w \mathrm{~km}$, from dip equator to zero current; all at $10^{\circ}$ intervals of longitude in September equinox derived from satellite data.

\begin{tabular}{crrrrrrr}
\hline $\begin{array}{c}\text { Longitude } \\
E \text { degrees }\end{array}$ & $J_{\mathrm{m}} \mathrm{A} \cdot \mathrm{km}^{-1}$ & $x_{\mathrm{m}} \mathrm{km}$ & $J_{\mathrm{m}} / J_{0} \%$ & $K \mathrm{nT}$ & $X_{0} \mathrm{nT}$ & $w_{X} \mathrm{~km}$ & $w \mathrm{~km}$ \\
\hline 0 & -58 & 446 & -29 & 124 & 59 & 265 & 228 \\
10 & -52 & 496 & -30 & 109 & 55 & 289 & 253 \\
20 & -53 & 493 & -31 & 108 & 54 & 285 & 250 \\
30 & -64 & 448 & -28 & 145 & 70 & 271 & 231 \\
40 & -66 & 485 & -29 & 143 & 72 & 286 & 248 \\
50 & -63 & 488 & -30 & 134 & 67 & 286 & 249 \\
60 & -65 & 457 & -30 & 133 & 64 & 267 & 233 \\
70 & -74 & 461 & -31 & 151 & 73 & 268 & 234 \\
80 & -88 & 415 & -27 & 203 & 93 & 256 & 215 \\
90 & -114 & 505 & -33 & 218 & 110 & 283 & 253 \\
100 & -103 & 437 & -29 & 224 & 105 & 261 & 224 \\
110 & -67 & 486 & -31 & 138 & 69 & 281 & 247 \\
120 & -72 & 440 & -29 & 157 & 74 & 263 & 226 \\
130 & -63 & 487 & -31 & 129 & 65 & 282 & 247 \\
140 & -58 & 493 & -30 & 122 & 62 & 286 & 251 \\
150 & -45 & 478 & -30 & 94 & 47 & 278 & 243 \\
160 & -45 & 468 & -31 & 92 & 45 & 272 & 238 \\
170 & -55 & 450 & -31 & 112 & 53 & 261 & 228 \\
180 & -96 & 494 & -32 & 190 & 96 & 281 & 249 \\
190 & -92 & 494 & -31 & 186 & 94 & 284 & 250 \\
200 & -62 & 458 & -31 & 127 & 61 & 267 & 233 \\
210 & -59 & 473 & -29 & 126 & 62 & 279 & 242 \\
220 & -38 & 441 & -28 & 84 & 40 & 264 & 226 \\
230 & -37 & 521 & -33 & 70 & 36 & 291 & 261 \\
240 & -53 & 442 & -30 & 111 & 52 & 260 & 225 \\
250 & -62 & 445 & -29 & 133 & 63 & 264 & 228 \\
260 & -74 & 466 & -32 & 148 & 72 & 268 & 236 \\
270 & -105 & 447 & -31 & 214 & 101 & 260 & 227 \\
280 & -101 & 463 & -31 & 204 & 99 & 267 & 234 \\
290 & -93 & 509 & -33 & 177 & 90 & 285 & 255 \\
300 & -96 & 465 & -30 & 199 & 97 & 271 & 236 \\
310 & -88 & 461 & -30 & 187 & 91 & 271 & 236 \\
320 & -72 & 471 & -30 & 151 & 74 & 277 & 241 \\
330 & -56 & 498 & -31 & 112 & 57 & 285 & 252 \\
340 & -72 & 479 & -31 & 146 & 72 & 276 & 242 \\
350 & -74 & 437 & -31 & 151 & 70 & 255 & 222 \\
\hline Mean & -70 & 469 & -30 & 146 & 71 & 273 & 239 \\
SD $\sigma$ & \pm 20 & \pm 25 & \pm 1 & \pm 40 & \pm 19 & \pm 10 & \pm 11 \\
\hline & & & & & & &
\end{tabular}


The parameter $K$ which appears in all expressions for the magnetic field of the EEJ derived from the model stands for the magnetic field of an infinite current sheet with constant intensity $J_{0}$. Onwumechili and Agu determined $K$ from the POGO equinox data at $10^{\circ}$ intervals of east longitude and these are given in Table 1 . Their sectoral means are plotted in Fig. 1.

The highest northward magnetic component of the EEJ is $X_{0}$, which occurs at the magnetic dip equator under the axis of the EEJ where $u=0$. To compute this from Eq. (3) we need values of $b$ and $v$ in addition to the other parameters already used above. Recently, Onwumechili and Ozoemena determined from the data of 17 rocket measurements of EEJ current density that $b=9.47 \pm 0.46 \mathrm{~km}$. Since we are interested in $X_{0}$ on the earth's surface, $v$ represents the altitude of the peak density of the electrojet. SAMPATH and SASTRY (1979) determined this altitude as $106 \pm 1.5 \mathrm{~km}$ in India while DAVIS et al. (1967) gave it as near $107 \mathrm{~km}$ off the coast of Peru. We therefore adopt $v=106 \mathrm{~km}$. With all these parameters we have computed $X_{0}$ at $u=0$ from Eq. (3) and the result is given in Table 1. The sectoral means are plotted in Fig. 2.

From this highest value, $X_{0}$, at the dip equator, $X$ decreases to zero at the field focus with a focal distance of $w_{X}$ from the dip equator given by

$$
\left(w_{X}+b\right)^{2}=-\frac{(v+\alpha v+2 a)(v+a)^{2}}{(v+\alpha v+2 \alpha a)} .
$$

The values of $w_{X}$ are given in Table 1 and plotted in Fig. 2.

The field $X$ then becomes negative and proceeds to a minimum value of $X_{\mathrm{m}}$ at a distance $u_{\mathrm{m}}$ from the magnetic dip equator given by

$$
\text { (sg. z) } X_{\mathrm{m}}=-\frac{K(v+\alpha v+2 \alpha a)^{2}}{16(1-\alpha)(v+a)^{2}}
$$

and

$$
\left(u_{\mathrm{m}}+b\right)^{2}=-\frac{(v+\alpha v+4 a-2 \alpha a)(v+a)^{2}}{(v+\alpha v+2 \alpha a)} .
$$

The values of $X_{\mathrm{m}}$ and $u_{\mathrm{m}}$ are given in Table 2 at $10^{\circ}$ intervals of east longitude, and their sectoral means in Fig. 2.

In the calculation of $X_{0}$ from Eq. (3) it was found that, to the nearest nT, there was no difference between the value of $X_{0}$ at $u=0$ obtained from the full expression and that obtained by neglecting the first term of the numerator and first term of the denominator of Eq. (3), which are much smaller than the terms following them. Neglecting these first terms simplifies the ratio of $X_{\mathrm{m}}$ to $X_{0}$, as reflected in the expression 


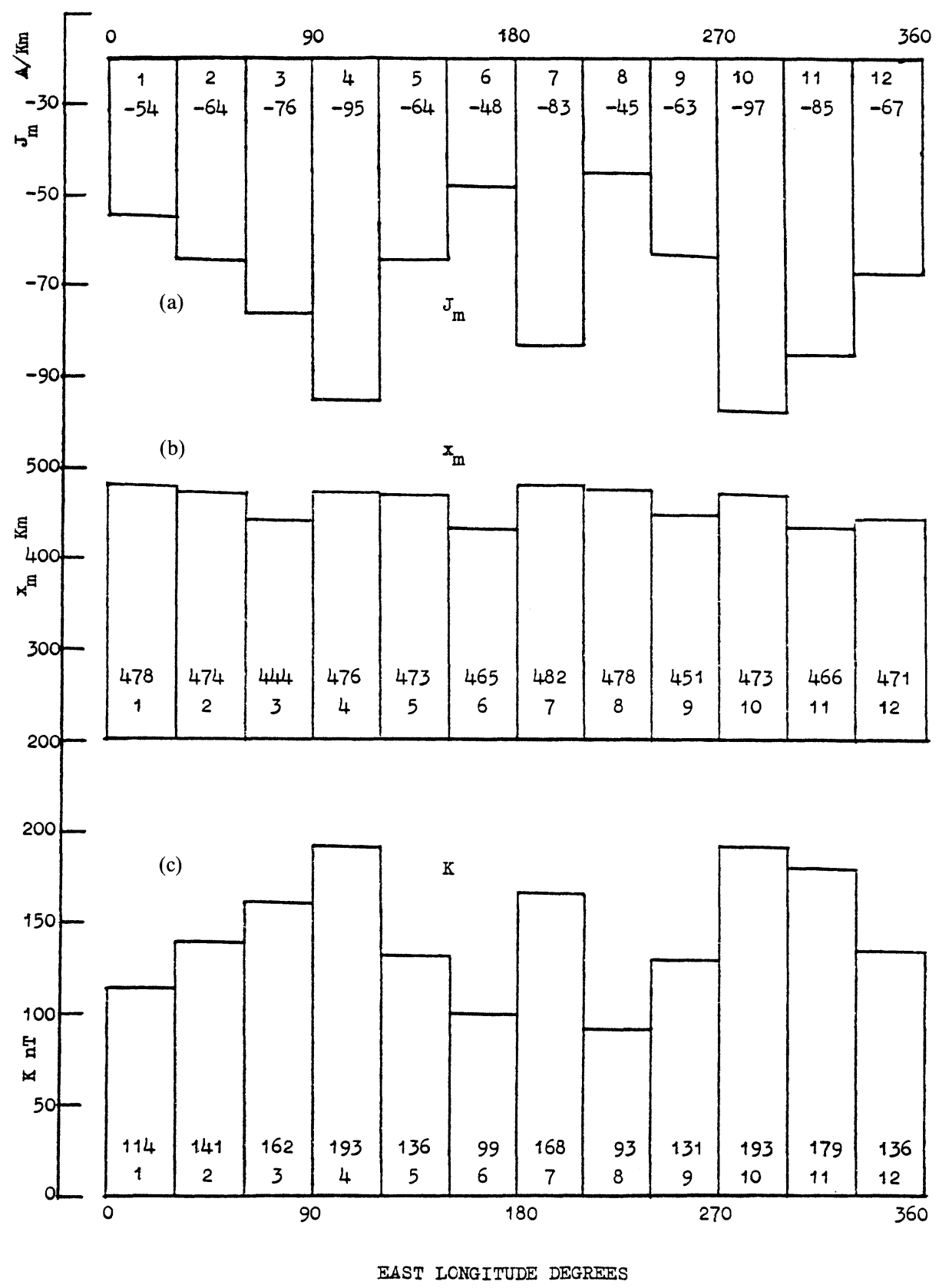

Fig. 1. Variation of $30^{\circ}$ sectoral means of equatorial electrojet (a) $J_{\mathrm{m}} \mathrm{A} \cdot \mathrm{km}^{-1}$, minimum eastward current intensity (here westward); (b) $x_{\mathrm{m}} \mathrm{km}$, distance from dip equator to minimum intensity; and (c) $K \mathrm{nT}$, magnetic field constant; all derived from September equinox satellite data. 


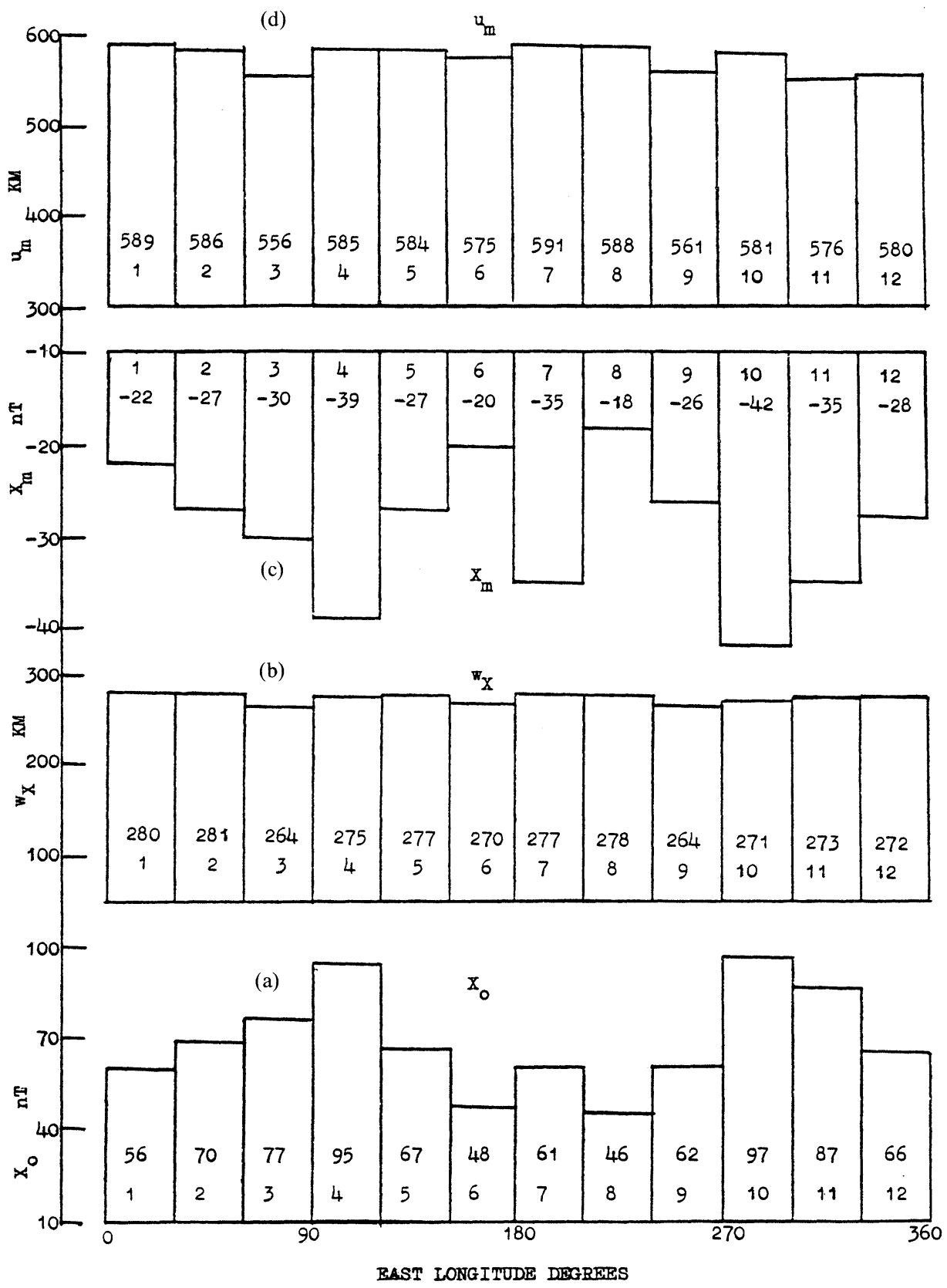

Fig. 2. Variation of $30^{\circ}$ sectoral means of equatorial electrojet (a) $X_{0} \mathrm{nT}$, maximum northward magnetic field at dip equator; (b) $w_{X} \mathrm{~km}$, distance from dip equator to zero northward magnetic field; (c) $X_{\mathrm{m}} \mathrm{nT}$, minimum northward magnetic field; and (d) $u_{\mathrm{m}} \mathrm{km}$, distance from dip equator to minimum northward field; all derived from September equinox satellite data. 
Table 2. Showing equatorial electrojet $X_{\mathrm{m}} \mathrm{nT}$, minimum northward magnetic field (here southward); $X_{\mathrm{m}} / X_{0}$, percentage of peak southward to peak northward magnetic field; $Z_{0} \mathrm{nT}$, vertical magnetic field at dip equator; $Z_{\mathrm{M}} \mathrm{nT}$, maximum vertical magnetic field; $Z_{\mathrm{M}} / X_{0}$, percentage of peak vertical to peak northward magnetic field; and distances: $u_{\mathrm{m}} \mathrm{km}$, from dip equator to minimum northward magnetic field; $u_{\mathrm{M}} \mathrm{km}$, from dip equator to maximum vertical magnetic field; $w_{Z} \mathrm{~km}$, from dip equator to zero vertical magnetic field; all at $10^{\circ}$ intervals of longitude in September equinox derived from satellite data.

\begin{tabular}{|c|c|c|c|c|c|c|c|c|}
\hline $\begin{array}{l}\text { Longitude } \\
E \text { degrees }\end{array}$ & $X_{\mathrm{m}} \mathrm{nT}$ & $u_{\mathrm{m}} \mathrm{km}$ & $X_{\mathrm{m}} / X_{0} \%$ & $Z_{0} \mathrm{nT}$ & $Z_{\mathrm{M}} \mathrm{nT}$ & $u_{\mathrm{M}} \mathrm{km}$ & $Z_{\mathrm{M}} / X_{0} \%$ & $w_{Z} \mathrm{~km}$ \\
\hline 0 & -23 & 558 & -39 & 4 & 47 & 205 & 80 & 831 \\
\hline 10 & -22 & 607 & -40 & 3 & 44 & 224 & 80 & 906 \\
\hline 20 & -22 & 603 & -41 & 3 & 44 & 222 & 81 & 889 \\
\hline 30 & -26 & 562 & -37 & 4 & 54 & 206 & 77 & 860 \\
\hline 40 & -28 & 597 & -39 & 4 & 58 & 219 & 81 & 899 \\
\hline 50 & -26 & 599 & -39 & 4 & 54 & 220 & 81 & 897 \\
\hline 60 & -26 & 567 & -41 & 4 & 51 & 209 & 80 & 833 \\
\hline 70 & -30 & 571 & -41 & 4 & 59 & 211 & 81 & 837 \\
\hline 80 & -34 & 530 & -37 & 6 & 72 & 193 & 77 & 813 \\
\hline 90 & -49 & 611 & -45 & 6 & 91 & 227 & 83 & 876 \\
\hline 100 & -41 & 549 & -39 & 6 & 83 & 202 & 79 & 821 \\
\hline 110 & -28 & 595 & -41 & 4 & 55 & 220 & 80 & 877 \\
\hline 120 & -29 & 552 & -39 & 5 & 59 & 203 & 80 & 827 \\
\hline 130 & -26 & 597 & -40 & 4 & 52 & 220 & 78 & 880 \\
\hline 140 & -25 & 604 & -40 & 3 & 49 & 222 & 79 & 898 \\
\hline 150 & -19 & 589 & -40 & 3 & 37 & 217 & 79 & 871 \\
\hline 160 & -19 & 578 & -42 & 3 & 36 & 213 & 80 & 848 \\
\hline 170 & -23 & 559 & -43 & 3 & 43 & 206 & 81 & 813 \\
\hline 180 & -41 & 602 & -43 & 5 & 77 & 223 & 80 & 875 \\
\hline 190 & -39 & 604 & -41 & 5 & 78 & 223 & 83 & 886 \\
\hline 200 & -25 & 568 & -41 & 4 & 49 & 210 & 80 & 832 \\
\hline 210 & -24 & 584 & -39 & 4 & 49 & 215 & 79 & 877 \\
\hline 220 & -15 & 553 & -38 & 2 & 31 & 203 & 78 & 834 \\
\hline 230 & -16 & 627 & -44 & 2 & 30 & 233 & 83 & 900 \\
\hline 240 & -21 & 552 & -40 & 3 & 42 & 203 & 81 & 812 \\
\hline 250 & -25 & 557 & -40 & 4 & 50 & 206 & 79 & 831 \\
\hline 260 & -31 & 574 & -43 & 4 & 58 & 213 & 81 & 835 \\
\hline 270 & -43 & 556 & -43 & 6 & 82 & 205 & 81 & 811 \\
\hline 280 & -42 & 571 & -42 & 6 & 80 & 211 & 81 & 831 \\
\hline 290 & -40 & 615 & -44 & 5 & 74 & 229 & 82 & 884 \\
\hline 300 & -40 & 574 & -41 & 6 & 78 & 212 & 80 & 845 \\
\hline 310 & -36 & 572 & -40 & 5 & 72 & 211 & 79 & 851 \\
\hline 320 & -29 & 582 & -39 & 4 & 59 & 214 & 80 & 868 \\
\hline 330 & -23 & 607 & -40 & 3 & 46 & 224 & 81 & 888 \\
\hline 340 & -30 & 587 & -42 & 4 & 58 & 217 & 81 & 859 \\
\hline 350 & -30 & 546 & -43 & 4 & 57 & 202 & 81 & 797 \\
\hline Mean & -29 & 579 & -41 & 4 & 57 & 214 & 80 & 855 \\
\hline $\mathrm{SD} \sigma$ & \pm 8 & \pm 23 & \pm 2 & \pm 1 & \pm 16 & \pm 9 & \pm 1 & \pm 31 \\
\hline
\end{tabular}




$$
8(1-\alpha) a(v+\alpha v+2 a) X_{\mathrm{m}}=-(v+\alpha v+2 \alpha a)^{2} X_{0} .
$$

The ratio of the minimum field $X_{\mathrm{m}}$ to the highest field $X_{0}$ is given in $10^{\circ}$ intervals of east longitude in percentage in Table 2.

\section{Vertical Magnetic Field Component of the Equatorial Electrojet}

When the complicated expression for the downward vertical magnetic field component of the equatorial electrojet, $Z$, is approximated in the same way as for $X$, then

$$
-(\operatorname{sg} . x) Z=\frac{1}{2} K a \frac{(u+b)\left[(1+\alpha)(u+b)^{2}+(v+\alpha v+3 a-\alpha a)(v+a)\right]}{\left[(u+b)^{2}+(v+a)^{2}\right]^{2}},
$$

where (sg. $x)$ is the sign of $x$.

From our values of the parameters the values of $Z_{0}$, at the magnetic dip equator on the earth where $u=0$ in Eq. (8), are computed and given in Table 2.

Close to the dip equator the first terms of the numerator and denominator of Eq. (8) are very small compared with the terms following them. Neglecting them, $Z$ in that region is given by

$$
-(\operatorname{sg} . x) Z=\frac{1}{2} \frac{K a(v+\alpha v+3 a-\alpha a)}{(v+a)^{3}}(u+b) .
$$

Therefore, in that neighbourhood the magnitude of $Z$ grows linearly with the effective distance $(u+b)$, though the real distance is $u$ from the dip equator, and with a gradient proportional to the intensity of the electrojet. Thus $Z$ is not zero at the dip equator because the effective distance there is not zero but $b$.

From the small value at the dip equator, $Z$ quickly proceeds to a minimum to the north and a maximum of equal magnitude to the south of the dip equator. With the usual approximations, the maximum $Z_{M}$ and the minimum occur at equal distances $u_{\mathrm{M}}$ on opposite sides of the dip equator, and are given by

$$
\begin{aligned}
& \left(u_{\mathrm{M}}+b\right)^{2}=\frac{(v+\alpha v+3 a-\alpha a)(v+a)^{2}}{6(1-\alpha) a}, \text { and } \\
& -(\operatorname{sg} . x) Z_{\mathrm{M}}=\frac{1}{2} K a \frac{[6(1-\alpha) a+(1+\alpha)(v+a)](v+\alpha v+3 a-\alpha a)^{2}}{\left(u_{\mathrm{M}}+b\right)(v+a)[6(1-\alpha) a+(v+\alpha v+3 a-\alpha a)]^{2}} .
\end{aligned}
$$

The values of $Z_{\mathrm{M}}$ and $u_{\mathrm{M}}$ are given in Table 2 at $10^{\circ}$ intervals of east longitude, and their sectoral means are plotted in Fig. 3. The percentage of $Z_{\mathrm{M}}$ to $X_{0}$ is also given in Table 2.

From the maximum and minimum, respectively, the magnitude of $Z$ slowly decreases to zero at a distance $w_{z}$ on both sides of the dip equator given by 


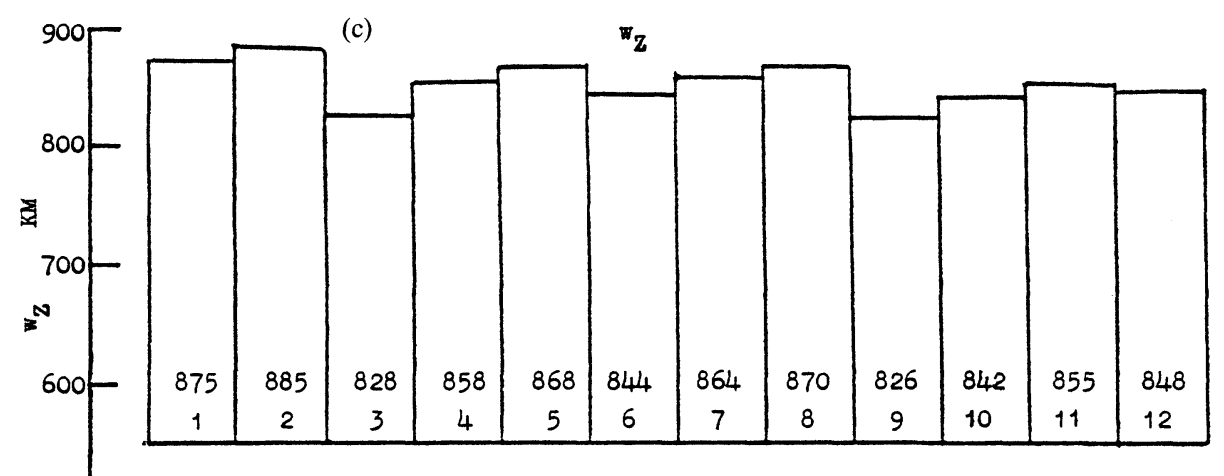

(b)
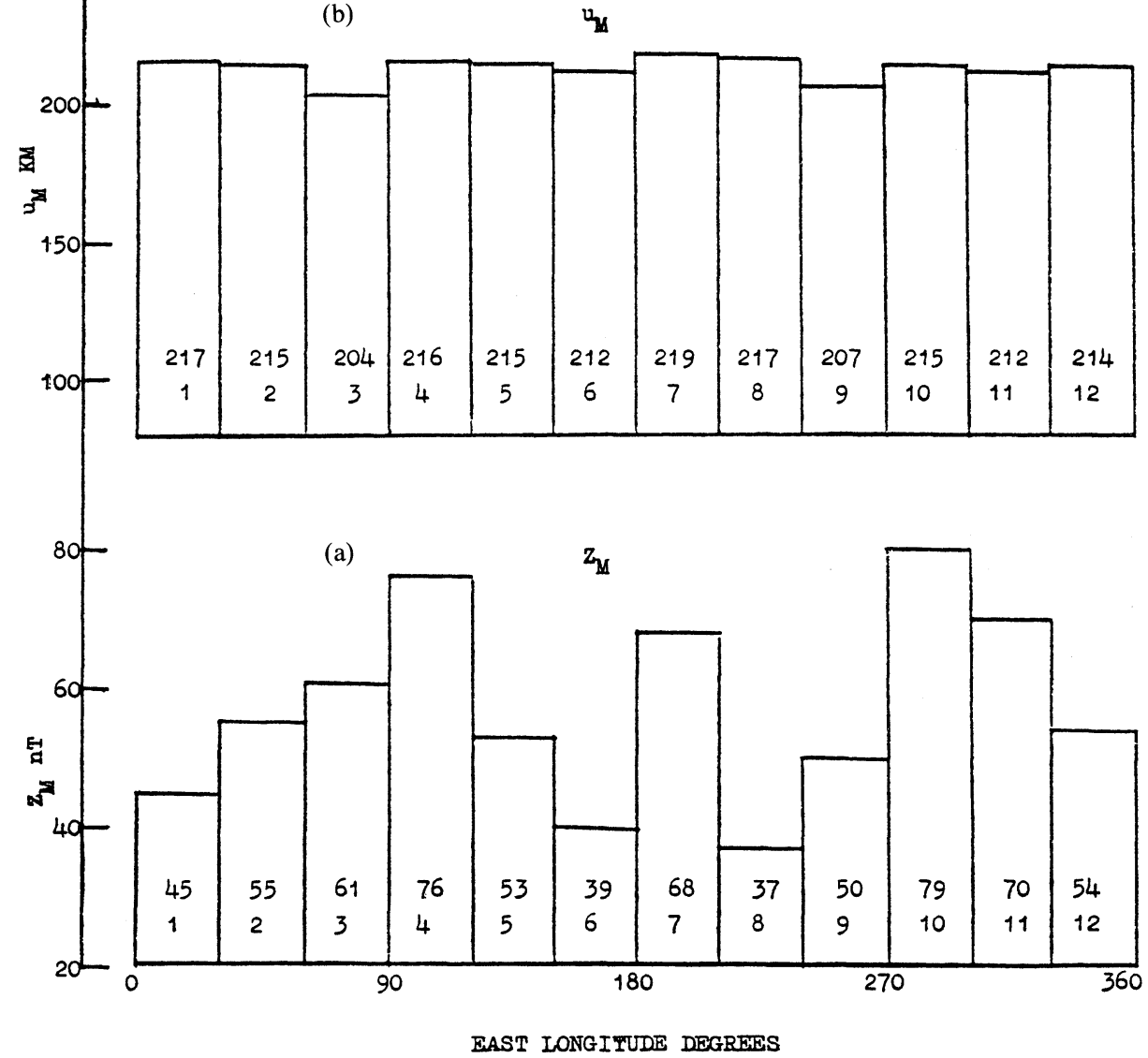

Fig. 3. Variation of $30^{\circ}$ sectoral means of equatorial electrojet (a) $Z_{M} n T$, maximum vertical magnetic field; (b) $u_{\mathrm{M}} \mathrm{km}$, distance from dip equator to maximum vertical field; and (c) $w_{Z} \mathrm{~km}$, distance from dip equator to zero vertical magnetic field; all derived from September equinox satellite data. 


$$
\left(w_{Z}+b\right)^{2}=-\frac{(v+\alpha v+3 a-\alpha a)(v+a)}{(1+\alpha)} .
$$

The values of $w_{z}$ at $10^{\circ}$ intervals of east longitude are given in Table 2 and their sectoral means are plotted in Fig. 3.

\section{Results and Discussions}

In this paper every effort has been made to avoid republishing any data that had been published before. However, because of some errors in the distance of the position of zero current density and intensity from the magnetic dip equator, $w \mathrm{~km}$ (called the half width of the electrojet), the corrected values of $w$ have been listed in Table 1. Because of this effort, the values of certain parameters used in the computation of results or discussions presented here have been omitted. The means of their 36 values at $10^{\circ}$ intervals of east longitude are: meridional scale length $a=326 \pm 19 \mathrm{~km}$, meridional distribution parameter $\alpha=-1.863 \pm 0.059$, peak eastward current intensity $J_{0}=232 \pm 63$ amperes per km, total eastward current $I_{+}=(54 \pm 11) \times$ $10^{3}$ amperes, and latitudinal extent of the EEJ $L_{1}=784 \pm 30 \mathrm{~km}$.

\subsection{Minimum current intensity}

When the model was proposed in 1965, it was recognized that the value of $\alpha$ was crucial. If $\alpha$ is positive, the extremal value $J_{\mathrm{m}}$ in Eq. (2) would exist only for $\alpha>2$, and in that case $J_{\mathrm{m}}$ would be a maximum rather than a minimum and there would be no westward (or return) current on the flanks of the dip equator. If $\alpha$ is negative $J_{\mathrm{m}}$ would be a minimum, and there would be westward (or return) current on the flanks of the dip equator.

By fitting actual ground-based observations of the EEJ, $\alpha$ came out negative with the above implications. About 15 years later, it became possible to determine $\alpha$ from satellite data processed differently from ground data. Here $\alpha$ again came out negative, and in reasonable agreement with its value from ground data.

ONWUMECHILI and OZOEMENA (1985) applied the principle of continuity of current to the model, and found that for the current to be nondivergent, $\alpha \leq-1$.

Furthermore, CAHILL (1959) observed westward current between $102 \mathrm{~km}$ and $108 \mathrm{~km}$ altitude on his rocket flight 83 at the location $\left(3.38^{\circ} \mathrm{N}, 158.68^{\circ} \mathrm{W}\right)$. Since the dip latitude of Jarvis $\left(0.4^{\circ} \mathrm{S}, 160.0^{\circ} \mathrm{W}\right)$ was $1.1^{\circ}$, the flight location was $4.88^{\circ}$, or 539 $\mathrm{km}$ north of the magnetic dip equator. Also, ANANDARAO and RAGHAVARAO (1979) found that when observed winds were incorporated in their model of the EEJ, westward currents resulted on the flanks of the dip equator.

We have therefore reached the point of being reasonably confident that Eq. (2) and the attendant results presented here are referring to a real westward, and most likely the return current, of the EEJ. The longitudinal variation of the intensity of this westward current is like that of the intensity of the eastward current presented by ONWUMECHILI and AGU (1981). With an average of $-70 \pm 20 \mathrm{~A} \cdot \mathrm{km}^{-1}$, the minimum intensity $J_{\mathrm{m}}$ has principal highest magnitudes of almost equal intensity 
around $90^{\circ} \mathrm{E}$ and $270^{\circ} \mathrm{E}$, and a subsidiary high magnitude around $180^{\circ} \mathrm{E}$. The smallest magnitudes are around $155^{\circ} \mathrm{E}$ and $225^{\circ} \mathrm{E}$.

From Table 1, the distance of the position of minimum current intensity, $x_{\mathrm{m}}$ $\mathrm{km}$, from the dip equator is $469 \pm 25 \mathrm{~km}$ and from Fig. 1, $x_{\mathrm{m}}$ does not vary systematically with longitude.

The ratio $J_{\mathrm{m}} / J_{0}$ of the peak westward intensity to the peak eastward intensity is $-30 \pm 1$ percent. This depends only on the meridional distribution parameter $\alpha$ and does not vary systematically with longitude. The ratio of the peak westward to the peak eastward intensity in the wind model of EEJ by Anandarao and Raghavarao is also $-29 \%$. MUSMANN and SEILER (1978) reported that westward current flowing at about $5^{\circ}$ from the dip equator with intensity of about $30 \%$ of the peak eastward intensity at the dip equator is implied by their observations in Brazil. These are in excellent agreement with our results.

It is also interesting to compare the results here arising from POGO equinoctial data with results from POGO solstitial data. For this, we have provided in Fig. 4 the so far unpublished sectoral variation of half width $w \mathrm{~km}$, peak eastward intensity $J_{0}$ $\mathrm{A} \cdot \mathrm{km}^{-1}$ and total eastward current $I_{+}$amperes for June 1969. The sectoral variation of $J_{\mathrm{m}}$ in Fig. 1 is similar to those of $J_{0}$ and $I_{+}$in Fig. 4. Also, both $x_{\mathrm{m}}$ in Fig. 1 and $w$ in Fig. 4 show no systematic variation with longitude.

\subsection{Northward magnetic field component}

The magnetic field constant $K$, with the average of $146 \pm 40 \mathrm{nT}$, being the magnetic field of an infinite plane current sheet of constant intensity $J_{0}$, is proportional of the peak eastward current intensity $J_{0}$. From Fig. 1 it has equal maximum values in sectors 4 and 10 and a subsidiary maximum in sector 7 . More specifically, the principal maxima occurred at $100^{\circ} \mathrm{E}$ and $270^{\circ} \mathrm{E}$ while the minima were at $160^{\circ} \mathrm{E}$ and $230^{\circ} \mathrm{E}$. This longitudinal variation is similar to those of $J_{0}$ and $I_{+}$ found by ONWUMECHILI and AGU (1981) from equinoctial data and those in Fig. 4 from solstitial data.

The northward magnetic field component at the magnetic dip equator $X_{0}$ has maxima of $110 \mathrm{nT}$ at $90^{\circ} \mathrm{E}, 96 \mathrm{nT}$ at $180^{\circ} \mathrm{E}$ and $101 \mathrm{nT}$ at $270^{\circ} \mathrm{E}$ in sectors 4,7 and 10 , respectively, minima of $45 \mathrm{nT}$ and $36 \mathrm{nT}$ at longitudes $160^{\circ} \mathrm{E}$ and $230^{\circ} \mathrm{E}$ in sectors 6 and 8 , respectively, and a mean of $71 \pm 19 \mathrm{nT}$. From the latitudinal profile electrojet survey of FORBUSH and CASAVERDE (1961), $X_{0}$ at $285^{\circ} \mathrm{E}$ in Peru was 90 $\mathrm{nT}$. This compares very well with $90 \mathrm{nT}$ at $290^{\circ} \mathrm{E}$ and $99 \mathrm{nT}$ at $280^{\circ} \mathrm{E}$ in Table 1. From a similar profile of OGBUEHI and ONWUMECHILI (1965) across the equatorial electrojet at September Equinox in Nigeria, $X_{0}$ at $5^{\circ} \mathrm{E}$ was $59 \mathrm{nT}$. Again, this compares very well with our $59 \mathrm{nT}$ at $0^{\circ} \mathrm{E}$ and $55 \mathrm{nT}$ at $10^{\circ} \mathrm{E}$ in Table 1 .

Like the other distances, $w_{X}$, the distance of the position of zero northward magnetic field component $X$, does not vary systematically with longitude and therefore its mean, $273 \pm 10 \mathrm{~km}$, may be used for any comparison. Unlike the presentations in the two profiles above, Hesse (private communication) has not presented the average profile from all the quiet days of his survey of the EEJ in Brazil. However, five of his profiles for October 17, 21 and 26, 1971, and November 


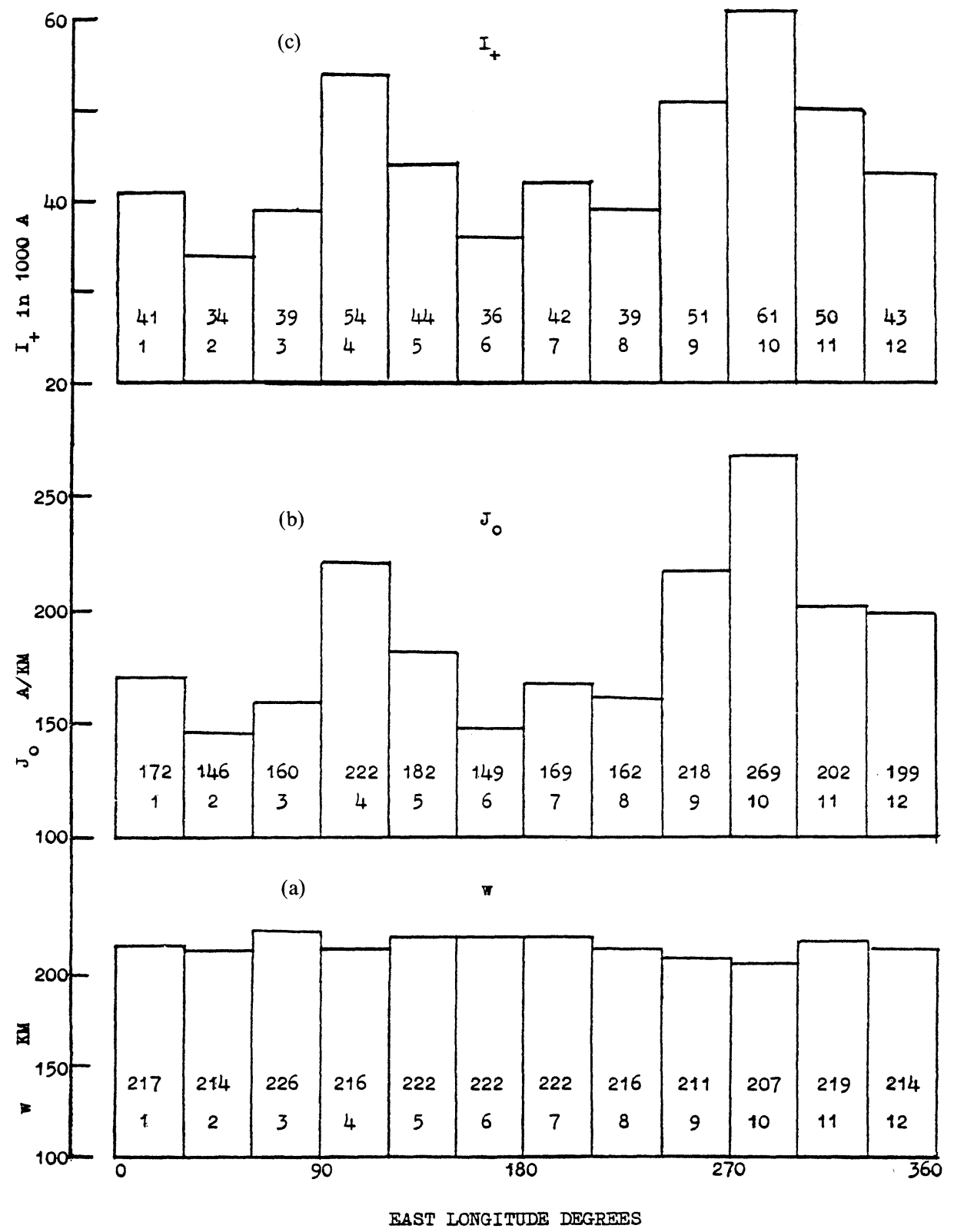

Fig. 4. Variation of $30^{\circ}$ sectoral means of equatorial electrojet (a) $w \mathrm{~km}$, distance from dip equator to zero current; (b) $J_{0} \mathrm{~A} \cdot \mathrm{km}^{-1}$, peak eastward current intensity; and (c) $I_{+}$in $10^{3} \mathrm{Amps}$, total eastward current; all derived from 1969 June solstice satellite data. 
14 and 16, 1971 are available to us and we made rough estimates of distances and ratios. From these $w_{X}$ has been estimated as $435 \pm 60 \mathrm{~km}$. The September equinox profile in Nigeria (ONWUMECHILI and OGBUEHI, 1967) gives $w_{X}$ as $424 \mathrm{~km}$. These ground-based values are higher than our value from satellite data. The difference may arise from underestimation of worldwide $S q(X)$, on which the extraction of $w_{X}$ from ground data depends.

The minimum northward magnetic field component of EEJ, $X_{\mathrm{m}}$ has major trough values of $-49 \mathrm{nT}$ at $90^{\circ} \mathrm{E}$ and $-43 \mathrm{nT}$ at $270^{\circ} \mathrm{E}$, a minor trough value of -41 $\mathrm{nT}$ at $180^{\circ} \mathrm{E}$, and crest values of $-19 \mathrm{nT}$ at $155^{\circ} \mathrm{E}$ and $-16 \mathrm{nT}$ at $225^{\circ} \mathrm{E}$ and a mean of $-29 \pm 8 \mathrm{nT}$. No available ground-based profile of the EEJ is suitable for the estimation of $X_{\mathrm{m}}$.

The mean value of the ratio $X_{\mathrm{m}} / X_{0}$ is $-41 \pm 2 \%$. A rough estimate of $X_{\mathrm{m}} / X_{0}$ from Hesse (private communication) gives $-32 \pm 6 \%$. This is in reasonable agreement with our finding.

The position of the minimum northward magnetic field component is at a distance of $u_{\mathrm{m}}$ from the dip equator. This does not vary systematically with longitude and has a mean of $579 \pm 23 \mathrm{~km}$. The only profile from which an estimate is possible (Hesse, private communication) gives $662 \pm 37 \mathrm{~km}$. The agreement is reasonably good.

It should be noted that the northward magnetic field positions are more distant than the corresponding current positions. $w_{X}$ exceeds $w$ by $34 \mathrm{~km}$ and $u_{\mathrm{m}}$ exceeds $x_{\mathrm{m}}$ by $110 \mathrm{~km}$. This is because the magnetic field of current at a point is inversely proportional to the distance of the point from the current. For example, reckoning from the position of zero current, the eastward (positive) current stretches from 0 to $478 \mathrm{~km}$, while the westward (negative) current stretches from 0 to $545 \mathrm{~km}$ on the near side and from $478 \mathrm{~km}$ to $1023 \mathrm{~km}$ on the far side. Consequently, even though the total positive equals the total negative current, judging the distances of the positive and negative portions of the current from the position of zero current, the field at that position is still positive. A similar consideration explains why $u_{\mathrm{m}}$ is beyond $x_{\mathrm{m}}$.

\subsection{Vertical magnetic field component}

Although the vertical magnetic field component at the dip equator, $Z_{0}$, is very small, it still indicates maxima in sectors 4,7 and 10 in its longitudinal variation, and has a mean of $4 \pm 1 \mathrm{nT}$. From the Peruvian profile of FORBUSH and CASAVERDE (1961), $Z_{0}$ was $8 \mathrm{nT}$ at $285^{\circ} \mathrm{E}$, in comparison with our finding of $6 \mathrm{nT}$ at $280^{\circ} \mathrm{E}$ and 5 $\mathrm{nT}$ at $290^{\circ} \mathrm{E}$. The Nigerian profile of OGBUEHI and ONWUMECHILI (1965) gave a $Z_{0}$ of $2 \mathrm{nT}$ and $5^{\circ} \mathrm{E}$ as compared to $4 \mathrm{nT}$ at $0^{\circ} \mathrm{E}$ and $3 \mathrm{nT}$ at $10^{\circ} \mathrm{E}$. Thus our findings of $Z_{0}$ are comparable to the values from ground-based profiles.

The longitudinal variation of the maximum vertical magnetic field component, $Z_{\mathrm{M}}$, is like that of the peak intensities and the other magnetic field values. It has principal maxima of $91 \mathrm{nT}$ at $90^{\circ} \mathrm{E}$ in sector 4 and $82 \mathrm{nT}$ at $270^{\circ} \mathrm{E}$ in sector 10 , with a subsidiary maximum of $78 \mathrm{nT}$ at $190^{\circ} \mathrm{E}$ in sector 7 . The minima are $36 \mathrm{nT}$ at $160^{\circ} \mathrm{E}$ in sector 6 and $30 \mathrm{nT}$ at $230^{\circ} \mathrm{E}$ in sector 8 , and the mean is $57 \pm 16 \mathrm{nT}$. $Z_{\mathrm{M}}$ was $36 \mathrm{nT}$ 
in the Nigerian profile (OGBueHI and ONWUMECHILI, 1965) at $5^{\circ} \mathrm{E}$, compared to our $47 \mathrm{nT}$ at $0^{\circ} \mathrm{E}$ and $44 \mathrm{nT}$ at $10^{\circ} \mathrm{E}$. In Peru, $Z_{\mathrm{M}}$ was $50 \mathrm{nT}$ to the North and $77 \mathrm{nT}$ to the South at $285^{\circ} \mathrm{E}$ because of the strong asymmetry there (ONWUMECHILI, 1967). Their mean of $64 \mathrm{nT}$ may be compared to our $80 \mathrm{nT}$ at $280^{\circ} \mathrm{E}$ and $74 \mathrm{nT}$ at $290^{\circ} \mathrm{E}$. Although still comparable, the profile values are lower than our values by about $10 \mathrm{nT}$, probably because they have been more affected by earth induction than our values, derived from satellite data.

The average of the ratio $Z_{\mathrm{M}} / X_{0}$ is $80 \pm 1 \%$, to be compared with $61 \%$ in the Nigerian profile, and $56 \%$ to the North and $86 \%$ to the South in the Peruvian profile; and $73 \pm 3 \%$ from the Brazilian profiles of Hesse (private communication). The mean profile ratio of $68 \pm 6 \%$ (from the three areas) is in reasonable agreement with ours, but is probably lower than ours for the same reason given in the preceeding paragraph.

The distance of maximum vertical magnetic field component, $u_{\mathrm{M}}$, does not vary systematically with longitude and has a mean of $214 \pm 9 \mathrm{~km} . u_{\mathrm{M}}$ was $275 \mathrm{~km}$ in the Nigerian profile (OGBUEHI and ONWUMECHILI, 1965) and $327 \mathrm{~km}$ to the north but $325 \mathrm{~km}$ to the south in the Peruvian profile (FORBUSH and CASAVERDE, 1961); and $333 \pm 5 \mathrm{~km}$ in Brazil. The profile mean of $311 \pm 32 \mathrm{~km}$ is comparable with our mean.

In general, the magnetic field values from ground-based profiles are in good agreement with our results, but the distances from the profiles tend to be greater than the distances derived from satellite data. ONWUMECHILI and OzOEMENA (1985) had also noted the same situation with regard to the half width $w$ and the latitudinal extent $L_{1}$ of the EEJ. CAIN and SWEENEY (1972) pointed out that latitudinal profiles of the EEJ are wider at greater altitudes and this has been reflected in all our expressions of the distances by $v$, the altitude of EEJ. In the first place, the rough estimates of the distances scaled from the profiles of investigators primarily interested in the magnetic field of the EEJ are far from being accurate. However, the general tendency suggests some basic difference, probably arising from the processing of the ground or the satellite data. One possibility is that the general background level of the worldwide $S q$ is underestimated in the ground profiles, while the general background of the ambient magnetic field $B$ is overestimated in the satellite profiles by measuring the magnitude of electrojet signature from the high shoulders of the profile.

All the intensities and magnetic fields share the same longitudinal variation, namely, principal maxima of about equal magnitude around longitudes $90^{\circ} \mathrm{E}$ and $270^{\circ} \mathrm{E}$ with a subsidiary maximum around longitude $180^{\circ} \mathrm{E}$, and minima around longitudes $155^{\circ} \mathrm{E}$ and $225^{\circ} \mathrm{E}$. These confirm the findings of $J_{0}$ and total eastward current $I_{+}$in ONWUMECHILI and AGU (1981) and OzOEMENA and ONWUMECHILI (1987), where possible explanations as well as the unexpected maximum around $90^{\circ} \mathrm{E}$ have been discussed. The subsidiary maximum is narrow and consequently looks isolated in a sectoral presentation. 


\section{Conclusions}

This study is important for two main reasons. First, it is the first study since all the parameters of the model have been estimated, and therefore certain approximations in its application have been dispensed with. Second, the only previous comprehensive comparisons of electrojet parameters from satellite and ground-based data were all for $X_{0}$ (reviewed in AGU and ONWUMECHILI (1981) and ONWUMECHILI (1985)) and $w$ and $L_{1}$ in ONWUMECHILI and OZEMENA (1985). This study makes a comprehensive comparison of nine additional parameters derived from satellite and ground-based data. Even if order of magnitude or no agreement exist, it would still be of interest. The following are among the conclusions from this study.

1) The minimum current intensity $J_{\mathrm{m}}$ is westwards, about $-70 \pm 20 \mathrm{~A} / \mathrm{km}$, and occurs at a distance of $x_{\mathrm{m}}$, about $469 \pm 25 \mathrm{~km}$ from the magnetic dip equator and on both sides of it. The percentage of the minimum to the maximum current intensity at the dip equator $J_{\mathrm{m}} / J_{0}$ is about $-30 \pm 1 \%$.

2) The maximum northward magnetic field component at the dip equator $X_{0}$ is about $71 \pm 19 \mathrm{nT}$, and this field decreases to zero at a distance of $w_{X}$ from the dip equator, about $273 \pm 10 \mathrm{~km}$.

3) The minimum northward magnetic field component $X_{\mathrm{m}}$ is negative (southwards) about $-29 \pm 8 \mathrm{nT}$, and occurs at a distance of $u_{\mathrm{m}}$, about $579 \pm 23 \mathrm{~km}$ from the dip equator. The percentage of the minimum to the maximum northward field $X_{\mathrm{m}} / X_{0}$ is about $-41 \pm 2 \%$.

4) At the dip equator, the vertical magnetic field component $Z_{0}$ is about $4 \pm 1$ $\mathrm{nT}$, and after growing to a maximum this field component eventually becomes zero at a distance of $w_{Z}$ from the dip equator, about $855 \pm 31 \mathrm{~km}$.

5) The maximum vertical magnetic field $Z_{M}$ is about $57 \pm 16 \mathrm{nT}$, and occurs at a distance of $u_{\mathrm{M}}$ from the dip equator, $u_{\mathrm{M}}$ being about $214 \pm 9 \mathrm{~km}$. The percentage of the maximum vertical field to the maximum northward field $Z_{\mathrm{M}} / X_{0}$ is about $80 \pm 1 \%$.

6) Variations of an eastward current are usually regarded as closely related to variations of its northward magnetic field component. We find, however, that the distance of zero northward field $w_{X}$ exceeds the distance of zero current $w$ by about $34 \mathrm{~km}$, and the distance of minimum northward field $u_{\mathrm{m}}$ exceeds the distance of minimum current $x_{\mathrm{m}}$ by about $110 \mathrm{~km}$, the difference in each case being more than three times the sample standard deviation. Given the westward (return) currents on the flanks of the dip equator, this has been explained as the consequence of the inverse distance law of the magnetic field of current.

7) There is excellent agreement between our ratio $J_{\mathrm{m}} / J_{0}$ and the findings of Musmann and Seiler (1978), and AnANDARAO and Raghavarao (1979); and also excellent agreement between our $x_{\mathrm{m}}$ and the location of the westward current measured by CAHILL (1959), and the findings of MUSMANN and SEILER (1978).

8) There is good agreement between the magnetic fields, $X_{0}, Z_{0}$ and $Z_{\mathrm{M}}$, derived from satellite and ground-based data. 
9) There is reasonable agreement between the ratios of the magnetic fields, $X_{\mathrm{m}} / X_{0}$ and $Z_{\mathrm{M}} / X_{0}$, derived from satellite and ground-based data.

10) Considering that the satellite and ground-based magnetic data are not contemporaneous, and the rough estimates of distances from ground-based profiles, the agreements between the landmark distances $w_{X}, u_{\mathrm{m}}$ and $u_{\mathrm{M}}$ and $w_{Z}$ derived from satellite and ground-based data are not disappointing. However, in view of the consistent tendency for the ground profile distances to exceed the distances derived from satellite data, the matter needs further investigation, such as paying particular attention to careful determination of all the landmark distances from ground-based data.

11) The intensities and magnetic fields, $J_{\mathrm{m}}, K, X_{0}, X_{\mathrm{m}}, Z_{0}$ and $Z_{\mathrm{M}}$, have the same longitudinal variation, characterized by principal maxima of about equal magnitude around longitudes $90^{\circ} \mathrm{E}$ and $270^{\circ} \mathrm{E}$ with a subsidiary maximum around $180^{\circ} \mathrm{E}$, and minima around longitudes $155^{\circ} \mathrm{E}$ and $225^{\circ} \mathrm{E}$.

12) The intensity and magnetic field ratios, $J_{\mathrm{m}} / J_{0}, X_{\mathrm{m}} / X_{0}$ and $Z_{\mathrm{M}} / X_{0}$, do not vary systematically with longitude. In each case the actual variation is small, the sample standard deviation being less than $5 \%$ of the mean.

13) The landmark distances, $x_{\mathrm{m}}, w_{X}, u_{\mathrm{m}}, u_{\mathrm{M}}$ and $w_{Z}$ do not vary systematically with longitude. The actual variation is also small, and in no case does the sample standard deviation exceed $5 \%$ of the mean.

\section{REFERENCES}

Agu, C. E. and C. A. Onwumechili, Comparison of the POGO satellite and ground measurements of the magnetic field of the equatorial electrojet, J. Atmos. Terr. Phys., 43, 801-807, 1981.

Anandarao, B. G. and R. Raghavarao, Effects of vertical shears in the zonal winds on the electrojet, Space Res., XIX, 283-286, 1979.

Cahill, L. J., Jr., Investigation of the equatorial electrojet by rocket magnetometer, J. Geophys. Res., 64, 489-503, 1959.

CAIn, J. C. and R. E. SweEney, POGO Observations of the Equatorial Electrojet, 54 pp., Goddard Space Flight Center Publications, X-645-72-299, 1972.

Davis, T. N., K. Burrows, and J. D. Stolarik, A latitude survey of the equatorial electrojet with rocket-borne magnetometers, J. Geophys. Res., 72, 1845-1861, 1967.

Forbush, S. E. and M. CaSAverde, The Equatorial Electrojet in Peru, 135 pp., Carnegie Institution of Washington Publication, No. 620, 1961.

Musmann, G. and E. Seiler, Detection of meridianal currents in the equatorial ionosphere, J. Geophys., 44, 357-372, 1978.

Ogbuehi, P. O. and C. A. Onwumechili, Seasonal studies of the equatorial electrojet during low solar activity, J. Geophys. Res., 70, 4909-4919, 1965.

Onwumechili, C. A., A three-dimensional model of density distribution in ionospheric currents causing part of quiet day geomagnetic variations, Proceedings of the Second International Symposium on Equatorial Aeronomy, edited by F. de Mendonca, pp. 387-390, Braxilian Space Commission, INPE, San Paulo, 1965.

Onwumechili, C. A., A new model of the equatorial electrojet current, Nigerian J. Sci., 1, 11-19, 1966.

Onwumechili, C. A., Geomagnetic variations in the equatorial zone, in Physics of Geomagnetic Phenomena, Vol. 1, edited by S. Matsushita and W. H. Campbell, pp. 425-503, Academic Press, New York, 1967. 
Onwumechili, C. A., Satellite measurements of the equatorial electrojet, J. Geomag. Geoelectr., 37, $11-36,1985$.

Onwumechili, C. A. and C. E. Agu, Longitudinal variation of the equatorial electrojet parameters derived from POGO satellite observations, Planet. Space. Sci., 29, 627-634, 1981.

Onwumechili, C. A. and P. O. Ogbuehi, Analysis of the magnetic field of the equatorial electrojet, $J$. Atmos. Terr. Phys., 29, 553-566, 1967.

Onwumechili, C. A. and P. C. Ozoemena, Latitudinal extent of the equatorial electrojet, J. Geomag. Geoelectr., 37, 193-204, 1985.

Ozoemena, P. C. and C. A. Onwumechili, Global variations of the POGO electrojet parameters during the solstices, J. Geomag. Geoelectr., 39, 625-636, 1987.

SAMPATH, S. and T. S. G. SASTRY, Results from in situ measurements of ionospheric currents in the equatorial region, Part I, J. Geomag. Geoelectr., 31, 373-379, 1979. 